\title{
Computerized Respiratory Sounds: Novel Outcomes for Pulmonary Rehabilitation in COPD
}

\author{
Cristina Jácome PT PhD and Alda Marques PT PhD
}

\begin{abstract}
BACKGROUND: Computerized respiratory sounds are a simple and noninvasive measure to assess lung function. Nevertheless, their potential to detect changes after pulmonary rehabilitation (PR) is unknown and needs clarification if respiratory acoustics are to be used in clinical practice. Thus, this study investigated the short- and mid-term effects of PR on computerized respiratory sounds in subjects with COPD. METHODS: Forty-one subjects with COPD completed a 12-week PR program and a 3-month follow-up. Secondary outcome measures included dyspnea, self-reported sputum, $\mathrm{FEV}_{1}$, exercise tolerance, self-reported physical activity, health-related quality of life, and peripheral muscle strength. Computerized respiratory sounds, the primary outcomes, were recorded at right/left posterior chest using 2 stethoscopes. Air flow was recorded with a pneumotachograph. Normal respiratory sounds, crackles, and wheezes were analyzed with validated algorithms. RESULTS: There was a significant effect over time in all secondary outcomes, with the exception of $\mathrm{FEV}_{1}$ and of the impact domain of the St George Respiratory Questionnaire. Inspiratory and expiratory median frequencies of normal respiratory sounds in the $100-300 \mathrm{~Hz}$ band were significantly lower immediately $(-2.3 \mathrm{~Hz}[95 \% \mathrm{CI}-4$ to -0.7$]$ and $-1.9 \mathrm{~Hz}[95 \% \mathrm{CI}-3.3$ to $-0.5])$ and at 3 months $(-2.1 \mathrm{~Hz}[95 \% \mathrm{CI}-3.6$ to -0.7$]$ and $-2 \mathrm{~Hz}[95 \% \mathrm{CI}-3.6$ to -0.5$])$ post-PR. The mean number of expiratory crackles $(-0.8,95 \%$ CI -1.3 to -0.3$)$ and inspiratory wheeze occupation rate (median 5.9 vs 0 ) were significantly lower immediately post-PR. CONCLUSIONS: Computerized respiratory sounds were sensitive to short- and mid-term effects of PR in subjects with COPD. These findings are encouraging for the clinical use of respiratory acoustics. Future research is needed to strengthen these findings and explore the potential of computerized respiratory sounds to assess the effectiveness of other clinical interventions in COPD. Key words: chronic lung disease; rehabilitation; computerized respiratory sounds. [Respir Care 2017;62(2):199-208. (C) 2017 Daedalus Enterprises]
\end{abstract}

\section{Introduction}

COPD affects 210 million people worldwide, ${ }^{1}$ placing a substantial burden on health-care systems. ${ }^{2}$ According to

Dr Jácome is affiliated with the Research Centre in Physical Activity, Health, and Leisure (CIAFEL), Faculty of Sports, University of Porto, Porto, Portugal and Lab 3R, Respiratory Research and Rehabilitation Laboratory, School of Health Sciences, University of Aveiro (ESSUA), Aveiro, Portugal. Dr Marques is affiliated with Lab 3R, Respiratory Research and Rehabilitation Laboratory, School of Health Sciences, University of Aveiro (ESSUA), Aveiro, Portugal and the Institute for Research in Biomedicine (BBiMED), University of Aveiro, Aveiro, Portugal.

This work was supported by Fundação para a Ciência e Tecnologia (FCT) Grant SFRH/BD/84665/2012. The authors have disclosed no conflicts of interest. the Global Initiative for Chronic Obstructive Lung Disease (GOLD), COPD is characterized by a persistent and progressive air flow limitation but also by its systemic consequences, mainly exacerbations and comorbidities. ${ }^{3}$ Clinical manifestations are thus highly variable, and no single outcome is able to assess the effectiveness of therapeutic interventions. ${ }^{4}$ In line with this evidence, the latest Amer-

\footnotetext{
Correspondence: Alda Marques PT PhD, Lab 3R, Respiratory Research and Rehabilitation Laboratory, School of Health Sciences, University of Aveiro (ESSUA), Agras do Crasto, Campus Universitário de Santiago, Edifício 30, 3810-193 Aveiro, Portugal. E-mail: amarques@ua.pt.
}

DOI: $10.4187 /$ respcare. 04987 
ican Thoracic Society/European Respiratory Society research statement on COPD recognizes that the effectiveness of interventions in COPD should be established using both patient-centered and surrogate outcomes. ${ }^{5}$

Pulmonary rehabilitation (PR) is one of the core components of the management of patients with COPD. ${ }^{6}$ Patientcentered outcomes, namely health-related quality of life, exercise capacity, and dyspnea, have been identified as the most important outcomes of PR. ${ }^{7}$ Surrogate outcomes, such as the $\mathrm{FEV}_{1}$, have also been used. ${ }^{4,8}$ However, unlike the other outcomes, $\mathrm{FEV}_{1}$ has not been found to be responsive to PR.4,8 Based on this evidence, and in the absence of another globally accepted surrogate outcome for lung function, it has been generally established that $\mathrm{PR}$ does not improve lung function in COPD. ${ }^{6}$ Nevertheless, FEV ${ }_{1}$ mainly reflects structural changes in the large airways, ${ }^{9}$ and it is well recognized that COPD primarily targets small airways. ${ }^{3}$ Hence, there is a need to explore new surrogate outcomes to assess the effects of PR on lung function.

Computerized respiratory sounds are a simple, objective, and noninvasive surrogate measure to assess the function of the respiratory system..$^{10}$ Computerized respiratory sounds can be divided into 2 main types, normal and adventitious. ${ }^{11}$ Normal respiratory sounds are generated by the air flow in the respiratory tract and characterized by broad-spectrum noise. ${ }^{11}$ Adventitious respiratory sounds are additional sounds, which can be continuous (wheezes) or discontinuous (crackles). ${ }^{11}$ Both normal and adventitious respiratory sounds are directly related to movement of air, changes within lung morphology, and the presence of secretions. ${ }^{10,12}$ In subjects with COPD, it has been shown that the number of detected wheezes, as well as their frequency, during forced expiratory maneuvers decreases after inhalation of terbutaline. ${ }^{13}$ It has also been demonstrated that it is possible to characterize the course of exacerbations of COPD in 2 different respiratory sound patterns based on the variation of spectral parameters. ${ }^{14}$ From the limited evidence, it can be hypothesized that computerized respiratory sounds have the potential to detect changes in lung function after PR. However, this is unknown because this measure has never been used to assess this intervention.

Thus, this study primarily aimed to investigate the shortand mid-term effects of PR on computerized respiratory sounds in subjects with COPD. The secondary aim was to explore correlations between computerized respiratory sounds and patient-centered outcomes.

\section{Methods}

\section{Design and Subjects}

This was a one-arm longitudinal study investigating the effects of PR on computerized respiratory sounds in subjects with COPD. Subjects with COPD were recruited from 2 primary care centers. Inclusion criteria were (1) diagno-

\section{QUICK LOOK}

\section{Current knowledge}

Based on $\mathrm{FEV}_{1}$, it has been generally established that pulmonary rehabilitation does not improve lung function in COPD. Nevertheless, $\mathrm{FEV}_{1}$ mainly reflects structural changes in the large airways, and it is well-recognized that COPD primarily targets small airways. Computerized respiratory sounds are a noninvasive measure to assess lung function, but their potential to detect changes in lung function after pulmonary rehabilitation is unknown.

\section{What this paper contributes to our knowledge}

Computerized respiratory sound parameters, namely median frequency of normal respiratory sounds, mean number of crackles, and wheeze occupation rate, were sensitive to short- and mid-term effects of pulmonary rehabilitation in subjects with COPD.

sis of COPD according to the GOLD, ${ }^{3}$ (2) age $\geq 40$ y old, and (3) clinical stability for 1 month before the study (ie, no hospital admissions or exacerbations as defined by GOLD or changes in medication for the respiratory system). ${ }^{3}$ Patients were excluded if they presented severe psychiatric, neurologic, or musculoskeletal conditions ${ }^{15}$ and/or unstable cardiovascular disease that could interfere with their performance during the exercise training sessions. The study was approved by the Center Health Regional Administration (2013-05-02) and by the National Data Protection Committee (3292/2013). Eligible patients identified via clinicians, were contacted by the researchers, who explained the purpose of the study and asked about their willingness to participate. When subjects agreed to participate, an appointment with the researchers was scheduled. Written informed consent was obtained before data collection.

\section{Intervention}

The PR program was held for 12 weeks and was composed of 3 weekly sessions of exercise training and one weekly session of psychoeducation. A detailed description of the program is provided elsewhere. ${ }^{16}$

\section{Data Collection}

Data were collected before and immediately after PR and then at 3 months post-PR. Two baseline computerized respiratory sound recordings with a 1-week interval before 
the intervention (hereafter referred to as baselines 1 and 2) were collected to confirm the stability of subjects' respiratory acoustics. ${ }^{17,18}$ At baseline 1 , socio-demographic, anthropometric (height and weight), and clinical (smoking habits, exacerbations in the previous year) data were first obtained. Dyspnea was assessed with the Modified British Medical Research Council questionnaire. ${ }^{3}$ Subjects' were classified using both the GOLD spirometric classification (mild, moderate, severe-to-very severe) and the GOLD combined assessment (A, B, C, and D). ${ }^{3}$ All assessments were performed by 2 physiotherapists, and the order was standardized.

\section{Outcome Measures}

Secondary Outcomes. Dyspnea at rest was assessed with the modified Borg scale. ${ }^{19}$ Subjects were asked to rate their dyspnea from 0 to 10 . Self-reported sputum was assessed using a numerical rating scale from 0 to 10 anchored at either end with a statement (no sputum at all $=0$; the worst sputum imaginable $=10$ ). Subjects were asked to select the number that best represented their subjective perception. ${ }^{20}$ To assess lung function, a spirometric test, using a portable spirometer (MicroLab 3500, CareFusion, Kent, United Kingdom), was performed according to standardized guidelines. ${ }^{21}$ Exercise tolerance was measured using the 6-min walk test. Two tests were performed according to the protocol described by the American Thoracic Society, 22 and the best performance was considered. To assess peripheral muscle strength, the knee extensor muscle strength of the dominant limb was determined by one repetition maximum (Multigym Plus G112X, BH, Vitoria-Gasteiz, Spain). ${ }^{23}$ For self-reported physical activity, a brief physical activity assessment tool, which consists of 2 questions assessing the frequency/duration of vigorous and moderate physical activity undertaken in a usual week, was used. ${ }^{24} \mathrm{~A}$ score of $\geq 4$ indicates that the subject is sufficiently active. ${ }^{24}$ Health-related quality of life was assessed using the St George Respiratory Questionnaire (SGRQ), with its 3 domains (symptoms, activities, and impact). ${ }^{25}$ Scores range from 0 (no impairment) to 100 (maximum impairment).

Primary Outcomes. After 5 min of quiet sitting, air flow and computerized respiratory sounds were acquired simultaneously during $20 \mathrm{~s}^{26}$ Subjects were in a seated-upright position, wearing a nose clip and breathing through a mouthpiece connected to a heated pneumotachograph (3830, Hans Rudolph, Shawnee, Kansas). A peak air flow of 0.4-0.6 $\mathrm{L} / \mathrm{s}$ was selected because computerized respiratory sounds have been shown to be reliable at this air flow range in subjects with COPD. ${ }^{27}$ Subjects had visual biofeedback of the flow signal (RSS 100R Research Pneumotach System, Hans Rudolph) and were instructed to maintain the flow between 2 horizontal lines. Recording was preceded by a training phase of at least 3 breathing cycles.

Recordings were performed simultaneously at right and left posterior chest $(5 \mathrm{~cm}$ laterally from the paravertebral line and $7 \mathrm{~cm}$ below the scapular angle) ${ }^{28}$ using the LungSounds@UA interface.29 Two chest pieces (Classic II S.E., Littmann, 3M, St. Paul, Minnesota), with a microphone (frequency response between $20 \mathrm{~Hz}$ and $19 \mathrm{kHz}$; TOM-1545P-R, Projects Unlimited, Dayton, Ohio) and preamplifier circuit (Intelligent Sensing Anywhere, Coimbra, Portugal) in the main tube, were attached to the subject's skin with adhesive tape (Soft Cloth Surgical Tape, 3M, St. Paul, Minnesota). The analog sound signals were further amplified and converted to digital by an audio interface (ProFire 2626, M-Audio, Irwindale, California). The signal was converted with a 24-bit resolution at a sampling rate of $44.1 \mathrm{kHz}$ and recorded in .wav format.

All generated files were processed using algorithms written in Matlab R2009a (Mathworks, Natick, Massachusetts). Breathing phases were automatically detected using the positive and negative air flow signals. Mean inspiratory and expiratory time were then calculated. The mean air flows and tidal volumes were calculated per breathing phase using flow and volume raw signals. The flow was timed synchronized with the sound to combine the detected breathing phases with sound signals.

Crackles were detected using a multi-algorithm technique based on established algorithms. ${ }^{30}$ This multi-algorithm technique showed a $7 \%$ performance improvement over the best individual algorithm. ${ }^{30}$ Wheezes were detected using an algorithm based on time-frequency analysis. ${ }^{31}$ The mean number of crackles and the wheeze occupation rate (proportion of the breathing phase occupied by wheezes) during inspiration and expiration were extracted per chest location (right and left posterior chest).

Normal respiratory sounds were analyzed based on the methodology proposed by Pasterkamp, ${ }^{32}$ after excluding adventitious respiratory sounds. The median frequency and the mean intensity were determined for the 2 most commonly analyzed frequency bands (ie, 100-300 and 300$600 \mathrm{~Hz})$ and extracted per breathing phase and per chest location. ${ }^{32,33}$

\section{Statistical Analysis}

A power calculation was not performed because there are no published data using computerized respiratory sounds to assess the effects of PR in subjects with COPD. Descriptive statistics were used to describe the sample and to examine the outcome measures. Differences between subjects who completed the study and dropouts were tested using independent $t$ tests for continuous normally distributed data, Mann-Whitney $U$ tests for 
continuous non-normally distributed data, and chi-square tests for categorical data.

Computerized respiratory sounds were explored between right and left posterior chest; however, no significant differences were found. Hence, data from both locations were pooled to simplify the interpretability of the findings.

Computerized respiratory sounds and breathing pattern (inspiratory/expiratory air flow, volume, and time) parameters were compared between baseline 1 and baseline 2 with paired $t$ tests for normally distributed data or the Wilcoxon signed-rank test for non-normally distributed data. After confirming that there were no significant differences, baseline 2, hereafter referred to as baseline, was used for further analysis.

Subjects were considered to have crackles or wheezes if they had at least a mean of one crackle/wheeze at baseline. To investigate differences in the number of subjects with crackles/wheezes across time points, the Cochran Q test was used, and Kendall's coefficient of concordance (Kendall's W) was reported as an estimate of effect size. ${ }^{34}$ This coefficient was interpreted as follows: very weak $(0-0.20)$, weak $(0.20-0.40)$, moderate $(0.40-0.60)$, strong $(0.60-.080)$, and very strong $(0.80-1.00)$ effect. $^{34}$ If the effect of time was significant, pairwise comparisons were performed using Bonferroni correction.

Normality was verified for all outcome measures. When data were normally distributed, one-way analysis of variance with repeated measures was used to establish the effects of time. The effect size was computed via partial $\eta$-squared, because it is the index more commonly reported in the analysis of variance. ${ }^{35}$ Partial eta-squared $\left(\eta^{2}\right)$ was interpreted as a small $(\geq 0.01)$, medium $(\geq 0.06)$, or large $(\geq 0.14)$ effect. ${ }^{35}$ When the effect of time was significant, post hoc analyses were conducted with pairwise comparisons using the Bonferroni correction to assess differences across the 3 time points (baseline, post$\mathrm{PR}$, and 3 months post-PR).

When data were not normally distributed, the Friedman test was used, together with the effect size estimate Kendall's W. ${ }^{34}$ If the effect of time was significant, post hoc analyses were conducted with Wilcoxon signed-rank tests using Bonferroni correction.

Because relationships between computerized respiratory sounds (median frequency, mean intensity, mean number of crackles, and wheeze occupation rate) and secondary outcome measures are yet little understood, correlations with Pearson's coefficient (r) or Spearman's rho $\left(r_{s}\right)$ were explored. Differences in breathing parameters across time were also explored with analyses of variance for repeated measures, because the breathing pattern can play a role in the genesis of normal ${ }^{36}$ and adventitious respiratory sounds. ${ }^{37,38}$

Statistical analyses were performed using IBM SPSS 20.0 (IBM, Armonk, New York), and plots were created

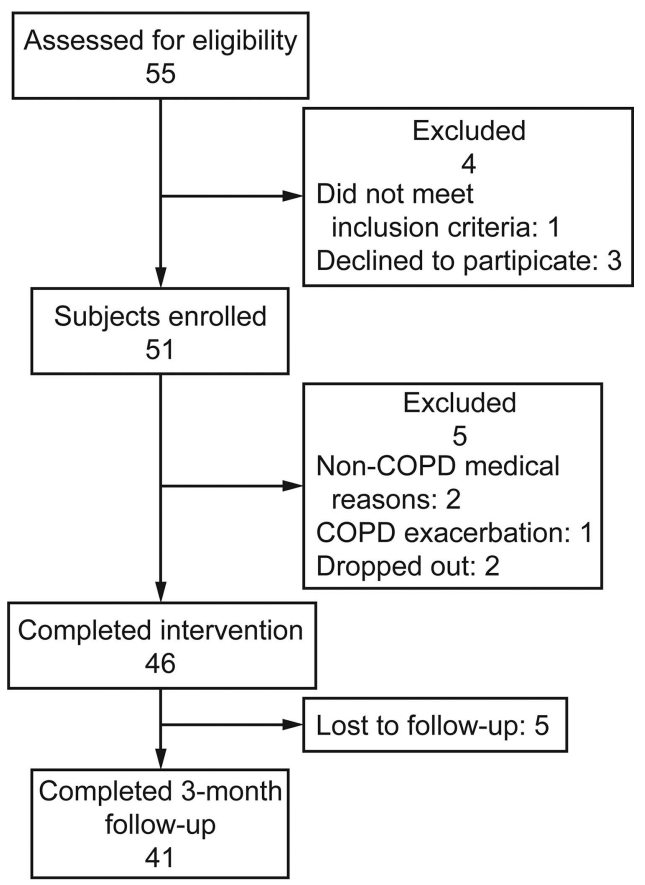

Fig. 1. Flow chart.

using GraphPad Prism 5.01 (GraphPad Software, La Jolla, California). The level of significance was set at .05.

\section{Results}

\section{Subjects}

A total of 51 subjects were enrolled; however, the final sample comprised 41 subjects (Fig. 1). Subjects were mostly male $(85 \%)$ and had a mean age of $67 \pm 9$ y old and a mean $\mathrm{FEV}_{1}$ of $69 \pm 22 \%$ of predicted (Table 1). There were no significant differences between completers and dropouts with regard to any of the baseline characteristics $(P>.05)$.

\section{Secondary Outcome Measures}

There was a significant effect over time in all secondary outcomes $\left(P<.007 ; \eta^{2}\right.$ from 0.12 to 0.61$)$, with the exception of $\operatorname{FEV}_{1}(P=.16)$ and SGRQ impact $(P=.35)$ (Table 2).

\section{Primary Outcome Measures}

Normal Respiratory Sounds. The inspiratory and expiratory median frequency of normal respiratory sounds changed only in the $100-300 \mathrm{~Hz}$ band $\left(P=.006, \eta^{2}=0.06\right.$; $\left.P=.01, \eta^{2}=0.05\right)$ (Fig. 2). Inspiratory median frequency was significantly lower immediately after PR and at 3 months post-PR compared with baseline $(-2.3 \mathrm{~Hz}$ 


\section{RESPIRATORy SOUNDS AS OUTCOMES FOR PR}

[95\% CI -4 to $-0.7 \mathrm{~Hz}], P=.006$ vs $-2.1 \mathrm{~Hz}$ [95\% CI -3.6 to $-0.7 \mathrm{~Hz}$ ], $P=.005$ ). Similar changes were observed in expiratory median frequency compared with baseline $(-1.9 \mathrm{~Hz}[95 \% \mathrm{CI}-3.3$ to $-0.5 \mathrm{~Hz}], P=.01$ vs $-2 \mathrm{~Hz}$ [95\% CI -3.6 to $-0.5 \mathrm{~Hz}$ ], $P=.009$ ).

No significant differences were seen in the $300-600 \mathrm{~Hz}$ band (inspiration $P=.42$ and expiration $P=.57$ ) (Fig. 2). Also, no significant differences in the mean intensity of normal respiratory sounds $(P>.05)$ were found (Fig. 2).

Immediately post-PR, there were weak to moderate relationships between inspiratory median frequency (300-600

Table 1. Subjects' Socio-Demographic and Clinical Characteristics

\begin{tabular}{|c|c|}
\hline Characteristics & Values \\
\hline Male sex, $n(\%)$ & $35(85)$ \\
\hline Age, mean $\pm \mathrm{SD}$ y & $67 \pm 9$ \\
\hline Current smokers, $n(\%)$ & $8(20)$ \\
\hline $\mathrm{BMI}$, mean $\pm \mathrm{SD} \mathrm{kg} / \mathrm{m}^{2}$ & $28 \pm 3$ \\
\hline mMRC, median (IQR) & $1(1-2)$ \\
\hline $\mathrm{FEV}_{1}$, mean $\pm \mathrm{SD} \%$ predicted $^{61}$ & $69 \pm 22$ \\
\hline $\mathrm{FEV}_{1} / \mathrm{FVC}$, mean $\pm \mathrm{SD}$ & $63 \pm 9$ \\
\hline \multicolumn{2}{|l|}{ GOLD spirometric classification, $n(\%)$} \\
\hline Mild & $17(42)$ \\
\hline Moderate & $16(39)$ \\
\hline Severe to very severe & $8(19)$ \\
\hline \multicolumn{2}{|l|}{ GOLD combined assessment, $n(\%)$} \\
\hline A & $14(34)$ \\
\hline $\mathrm{B}$ & $15(37)$ \\
\hline $\mathrm{C}$ and $\mathrm{D}$ & $12(29)$ \\
\hline $\begin{array}{l}N=41 \\
\text { BMI = body mass index } \\
\text { mMRC = Modified British Medical Research Council dyspnea scale } \\
\text { IQR = interquartile range } \\
\text { GOLD = Global Initiative for Chronic Obstructive Lung Disease }\end{array}$ & \\
\hline
\end{tabular}

$\mathrm{Hz}$ band $)$ and SGRQ symptoms $(\mathrm{r}=0.57, P<.001)$, SGRQ total $(\mathrm{r}=0.52, P=.001)$, rest dyspnea $(\mathrm{r}=0.41, P=.008)$, and self-reported sputum $(\mathrm{r}=0.33, P=.039)$.

Crackles. All subjects had inspiratory crackles across the different time points; however, the frequency of subjects with expiratory crackles decreased across time $(P=.005$; Kendall's $\mathrm{W}=0.13$ ). Expiratory crackles were present in all subjects before the intervention, whereas after PR, expiratory crackles were found in 34 subjects $(82.9 \%$, $P=.004)$ and at 3 months post-PR in 37 subjects $(90.2 \%$, $P=.19)$. Also, no significant difference was found in the frequency of subjects with expiratory crackles between post-PR and 3 months post-PR $(P=.49)$.

The mean number of inspiratory crackles did not change significantly across time $(P=.51)$ (Fig. 3). Expiratory crackles, however, changed across the 3 time points $\left(P=.01 ; \eta^{2}=0.07\right)$. Their mean number was significantly lower immediately after PR, compared with baseline ( -0.8 [95\% CI -1.3 to -0.3 ], $P=.003$ ) (Fig. 3).

After PR, weak to moderate positive relationships were found between the mean number of inspiratory $(\mathrm{r}=0.4$, $P=.01)$ and expiratory $(\mathrm{r}=0.33, P=.036)$ crackles and rest dyspnea. No other relationships were found.

Wheezes. The frequencies of subjects with inspiratory $(P=.006$, Kendall's $\mathrm{W}=0.08)$ and expiratory $(P=.002$; Kendall's $\mathrm{W}=0.09$ ) wheezes were different across time points. Twelve subjects (29.3\%) presented inspiratory, and $17(41.5 \%)$ presented expiratory wheezes before the intervention, whereas immediately after PR, the numbers were only $6(14.6 \%, P=.060)$ and $9(22 \%, P=.01)$, and at 3 months post-PR, they were $4(9.8 \%, P=.006)$ and 8

Table 2. Secondary Outcome Measures to Assess Pulmonary Rehabilitation Across Time

\begin{tabular}{|c|c|c|c|c|c|}
\hline Outcome Measure & Baseline & Immediately Post-PR & 3 Months Post-PR & $P$ & $\eta^{2}$ \\
\hline Dyspnea (0-10), median (IQR) & $1(0-2)$ & $1(0-2)^{*}$ & $0(0-1.75)^{*}$ & .007 & 0.12 \\
\hline Sputum (0-10), median (IQR) & $1.5(0-4)$ & $1(0-2)^{*}$ & $1(0-2)^{*}$ & .003 & 0.15 \\
\hline $\mathrm{FEV}_{1}$, mean $\pm \mathrm{SD} \%$ predicted $^{61}$ & $68.9 \pm 21.7$ & $67.1 \pm 21.8$ & $68 \pm 21.7$ & .16 & 0.05 \\
\hline $6 \mathrm{MWD}$, mean $\pm \mathrm{SD} \mathrm{m}$ & $481.3 \pm 76.1$ & $538.8 \pm 78.8^{*}$ & $525.2 \pm 75.5^{* \dagger} \dagger$ & $<.001$ & 0.51 \\
\hline Knee extensors, mean \pm SD kg & $37.9 \pm 8.5$ & $47.5 \pm 11.5^{*}$ & $41.8 \pm 11.1^{* \dagger}$ & $<.001$ & 0.61 \\
\hline Physical activity $(0-8)$, mean \pm SD & $1.8 \pm 2.0$ & $5.1 \pm 1.6^{*}$ & $3.4 \pm 2.3^{*} \dagger$ & $<.001$ & 0.45 \\
\hline SGRQ total $(0-100)$, mean \pm SD & $31.0 \pm 16.8$ & $24.2 \pm 17.6^{*}$ & $22.1 \pm 12.1^{*}$ & $<.001$ & 0.27 \\
\hline SGRQ symptoms $(0-100)$, mean \pm SD & $40.6 \pm 20.8$ & $33.0 \pm 18.8^{*}$ & $27.3 \pm 20.0^{*}$ & .003 & 0.14 \\
\hline SGRQ activities $(0-100)$, mean \pm SD & $46.9 \pm 19.6$ & $36.1 \pm 22.9$ & $28.6 \pm 22.1$ & $<.001$ & 0.19 \\
\hline SGRQ impact $(0-100)$, mean \pm SD & $18.7 \pm 16.9$ & $14.5 \pm 17.1$ & $15.3 \pm 16.5$ & .35 & 0.03 \\
\hline $\begin{array}{l}N=41 . \\
* \text { Significantly different from baseline. } \\
\dagger \text { Significantly different from post-PR. } \\
\mathrm{PR}=\text { pulmonary rehabilitation } \\
\eta^{2}=\text { partial eta-squared. } \\
\mathrm{IQR}=\text { interquartile range } \\
6 \mathrm{MWD}=6 \text {-min walk distance } \\
\mathrm{SGRQ}=\text { St George Respiratory Questionnaire }\end{array}$ & & & & & \\
\hline
\end{tabular}



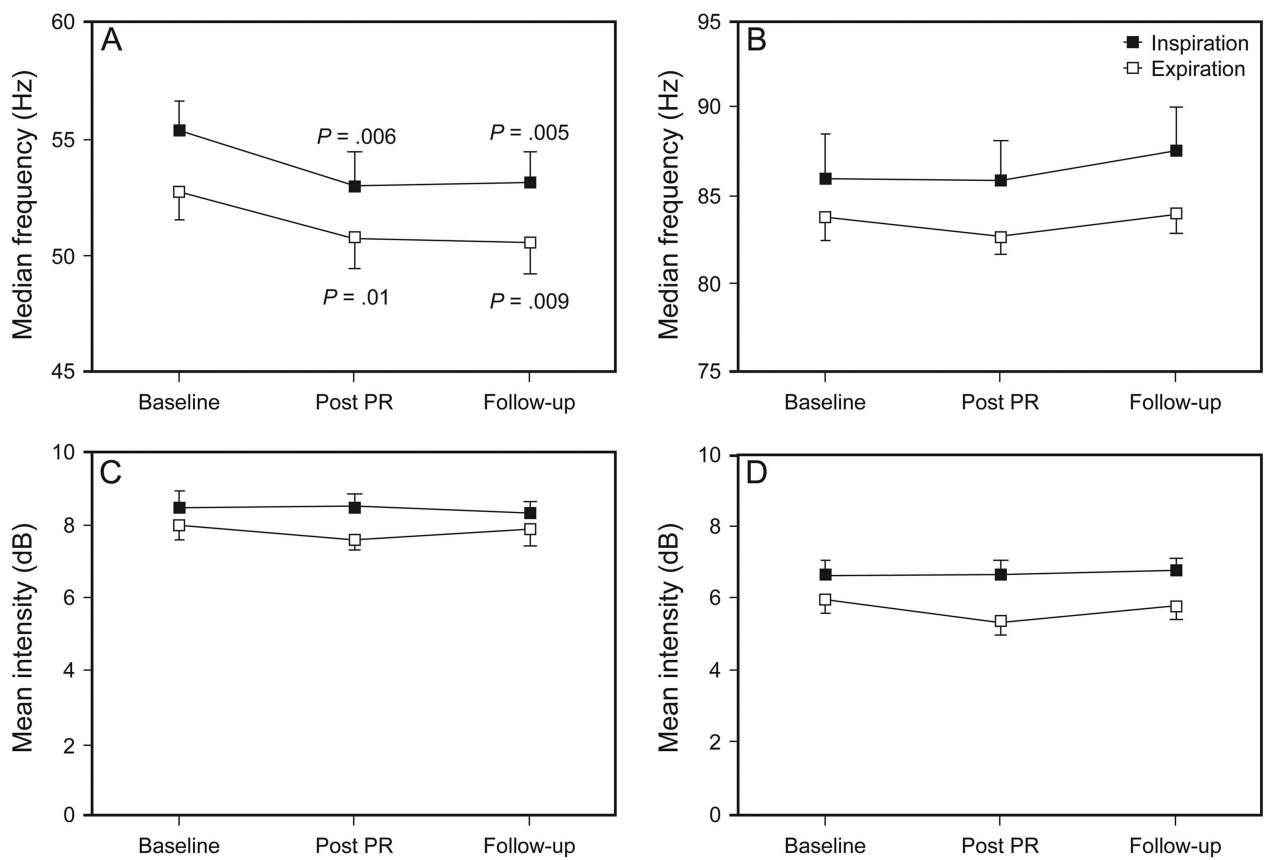

Fig. 2. Median frequency (A and $B$ ) and mean intensity ( $C$ and $D)$ of normal respiratory sounds at 2 frequency bands (100-300 Hz [A and $\mathrm{C}]$ and $300-600 \mathrm{~Hz}$ [B and $\mathrm{D}]$ ) at baseline, post-pulmonary rehabilitation (PR), and at 3-month follow-up. Data are presented as mean $\pm 95 \% \mathrm{Cl}$. $P$ values are difference from baseline.
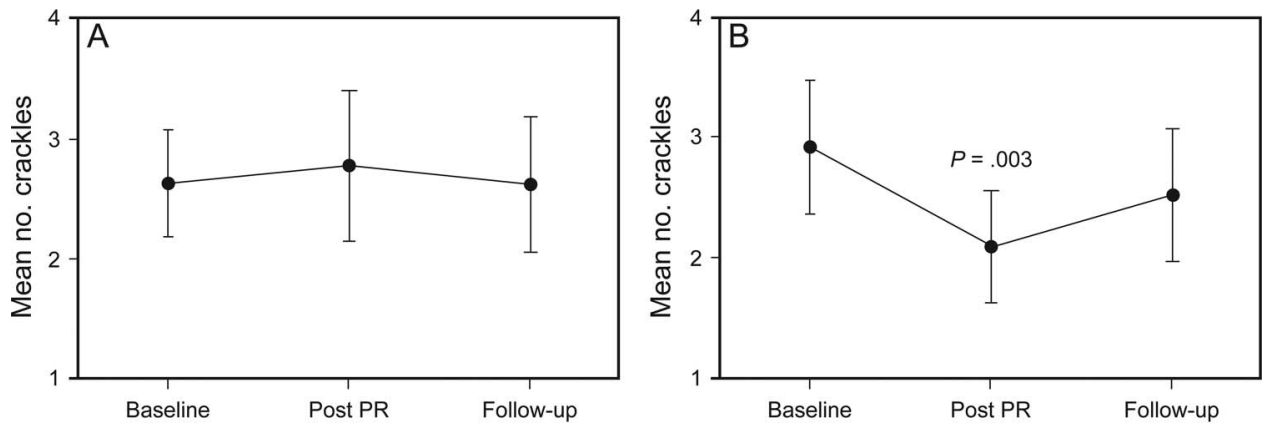

Fig. 3. Mean number of inspiratory $(A)$ and expiratory $(B)$ crackles at baseline, post-pulmonary rehabilitation (PR), and at 3-month follow-up. Data are presented as mean $\pm 95 \% \mathrm{Cl}$. $P$ value is difference from baseline.

$(19.5 \%, P=.004)$, respectively. No significant differences were observed in the frequency of subjects with inspiratory/expiratory wheezes between post-PR and 3 months post-PR $(P>.99)$.

Figure 4 shows the behavior of wheeze occupation rate over time of subjects with wheezes at baseline. The inspiratory wheeze occupation rate changed across the 3 time points $(P<.001$; Kendall's $\mathrm{W}=0.51)$. Post hoc analysis was conducted with a Bonferroni correction. The inspiratory wheeze occupation rate was significantly lower after PR (median 0) compared with the baseline (median $5.9, P=.001)$. Expiratory wheeze occupation rate changed significantly across time $(P=.003$; Kendall's $\mathrm{W}=0.31)$; however, during post hoc tests, no significant results were found. Only a tendency for lower expiratory wheeze oc- cupation rate after PR (median 0.8) compared with baseline (median 8.9) $(P=.035)$ was observed (Fig. 4).

In subjects with no inspiratory $(n=29 ; 70.7 \%)$ or expiratory $(n=24 ; 58.5 \%)$ wheezes at baseline, no significant differences in the behavior of inspiratory (medians of 0 at baseline, post-PR, and 3 months post-PR, $P=.77$ ) or expiratory (medians of 0 at baseline and 3 months post-PR and median of 2 post-PR, $P=.54$ ) wheeze occupation rates were found across the 3 time points.

A moderate correlation between expiratory wheeze occupation rate and $\mathrm{FEV}_{1}$ was verified $\left(\mathrm{r}_{\mathrm{s}}=-0.42, P=.008\right)$ before the intervention. No other relationships were found.

Breathing Pattern. No significant differences over time were observed in inspiratory/expiratory flow $(P=.057$ 

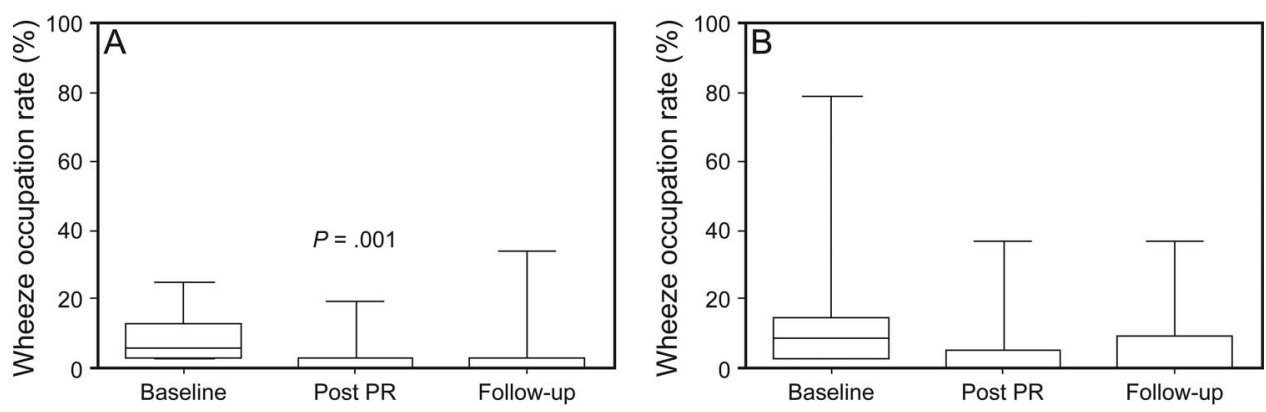

Fig. 4. Wheeze occupation rate during inspiration $(\mathrm{A}, n=12)$ and expiration $(\mathrm{B}, n=17)$ at baseline, post-pulmonary rehabilitation $(\mathrm{PR})$, and at 3-month follow-up. Data are presented as box and whisker plots with median, interquartile ranges, and $5-95 \%$ percentiles. $P$ value is difference from baseline.
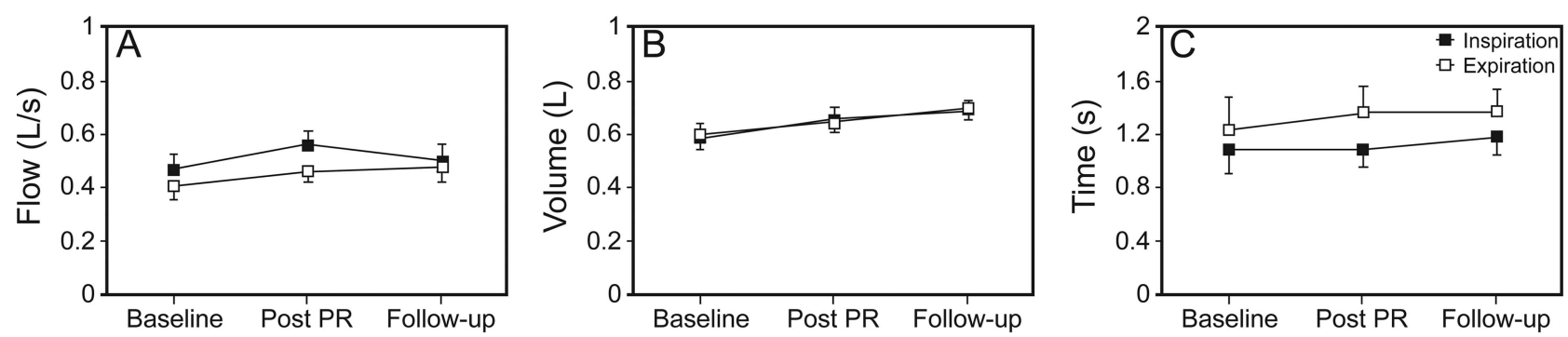

Fig. 5. Inspiratory and expiratory flow (A), volume (B), and time $(C)$ at baseline, post-pulmonary rehabilitation (PR), and at 3-month follow-up. Data are presented as mean $\pm 95 \% \mathrm{Cl}$.

and $P=.12)$, volume $(P=.14$ and $P=.18)$, or time $(P=.48$ and $P=.58)$ during the recordings of respiratory sounds (Fig. 5).

\section{Discussion}

To the best of the authors' knowledge, this is the first study investigating the effects of PR on computerized respiratory sounds in subjects with COPD. The main findings indicated that median frequency of normal respiratory sounds, number of crackles, and wheeze occupation rate were able to detect significant differences in lung function immediately post-PR and that most of these effects were not maintained at 3 months.

The mean frequency of normal respiratory sounds was sensitive to PR, whereas the intensity remained unchanged. Similar observations were reported by Malmberg et al, ${ }^{40}$ who found respiratory sound intensity at standardized air flows to be less informative than the median frequency as an indicator of flow obstruction in adults with asthma and healthy subjects. Sánchez-Morillo et al ${ }^{14}$ also found that median frequency was one of the respiratory sound parameters to better distinguish between 2 groups of subjects with exacerbation of COPD. Inspiratory and expiratory median frequency were significantly lower immediately and at 3 months post-PR. To the authors' knowledge, no published studies have tested the change in normal respi- ratory sounds after PR. Previous studies have demonstrated that higher median frequency values are related to pathologic events, such as bronchoconstriction and the presence of pneumonia ${ }^{14,40}$; therefore, the decrease in median frequency found in this study may reflect an improvement of lung function after PR. This decrease was only significant in the $100-300 \mathrm{~Hz}$ band, possibly because this frequency band is where, in stable conditions, most of the acoustic energy resides. ${ }^{10,41}$ Nevertheless, because bronchoconstriction and sputum generate flow-turbulent noise, and flow turbulence produces sounds in high frequency ranges, ${ }^{42}$ the frequency band of $300-600 \mathrm{~Hz}$ is also of clinical importance. Positive relationships between inspiratory median frequency and subjects' symptoms (SGRQ symptoms, rest dyspnea, self-reported sputum) and health-related quality of life (SGRQ total) were only found at this highfrequency band $(300-600 \mathrm{~Hz})$. Future studies assessing the effects of PR on normal respiratory sounds of subjects with exacerbation of COPD should therefore consider both low- and high-frequency bands.

The mean number of inspiratory crackles did not change across time, but it is well-known that COPD is characterized by inspiratory crackles. ${ }^{43,44}$ Moreover, the mean number of inspiratory crackles at the 3 time points was within the range of previously reported results. ${ }^{45-47}$ The mean number of expiratory crackles, however, was significantly lower immediately after PR. No studies have investigated 
the change in number of crackles in subjects with COPD after PR. A slight decrease in the number of expiratory crackles (from $0.8 \pm 0.8$ to $0.7 \pm 0.1$ ) after standard medical treatment has also been reported previously in 11 subjects with pneumonia. ${ }^{47}$ After PR, the slight, but consistent, reduction in the number of expiratory crackles may be due to a combination of a number of factors. First, the active airway clearance techniques practiced during the PR program may have enhanced sputum evacuation. ${ }^{48,49} \mathrm{~A}$ systematic review of the use of airway clearance techniques in subjects with COPD found that active airway clearance techniques were effective at removing secretions. ${ }^{49}$ Second, the participation in the PR program may have optimized the use of maintenance bronchodilator therapy, ${ }^{6}$ and it is known that bronchodilators act on airway smooth muscle, reducing air trapping and hyperinflation. ${ }^{50,51}$ Although not yet well understood, these airway changes might have been responsible for decreasing the genesis of crackles. Despite the possible explanatory reasons, the lower mean number of expiratory crackles after PR seems to point to an improvement in subjects' lung function. A recent study ${ }^{45}$ showed that expiratory crackles are significantly more frequent during periods of increased disease severity (exacerbations of COPD) than during stable periods (median 3.17 vs 0.83 ). Additionally, a positive correlation was found between crackles and rest dyspnea. To date, there are no references in the literature about this correlation. It is believed, however, that hyperinflation may explain this relationship, because it is fundamental to the origin of dyspnea ${ }^{39}$ and may contribute to the genesis of crackles.

The inspiratory wheeze occupation rate was significantly lower after PR compared with the baseline. A significant decrease in inspiratory wheeze occupation rate (from $9.2 \pm 14.1$ to $0.4 \pm 1.9 \%$ ) has been reported previously in 9 subjects with lower respiratory tract infection after 3 weeks of pharmacotherapy plus respiratory physical therapy..$^{52}$ Inspiratory wheezes have also been associated with more severe airway obstruction in subjects with asthma ${ }^{53}$ and are characteristic of exacerbations of COPD..$^{45}$ Based on this evidence, it is possible that the significant decrease in inspiratory wheeze occupation rate observed in this study reflects an improvement in subjects' airway obstruction after PR. The wheeze occupation rate during expiration did not change with PR. Expiratory wheezes, in contrast with inspiratory wheezes, are a common sign in patients with COPD, ${ }^{13,46}$ and baseline values were in line with earlier studies. ${ }^{46}$ It was also verified that the severity of air flow limitation was correlated with the expiratory wheeze occupation rate, with lower values of $\mathrm{FEV}_{1}$ producing a higher wheeze occupation rate, as shown previously by Fiz et al. ${ }^{13}$

No short- or mid-term improvement in $\mathrm{FEV}_{1}$ was observed after PR, which is in agreement with previous stud- ies. ${ }^{54,55}$ In light of this research, it has been established that PR does not improve lung function in COPD. ${ }^{6}$ However, $\mathrm{FEV}_{1}$ is only one possible parameter to measure lung function; inspiratory capacity, diffusing capacity, and respiratory sound parameters are examples of other possible surrogate outcomes. ${ }^{4}$ In this study, the potential of computerized respiratory sounds for assessing the shortterm effect of PR on lung function has been shown. This noteworthy finding demonstrates that respiratory sounds are a more sensitive indicator of the status of lung function than $\mathrm{FEV}_{1}$, which is in line with the study from Gavriely et al. ${ }^{56}$ In this study, half of the subjects with a history compatible with COPD had normal spirometry and abnormal respiratory sounds, revealing that airway abnormalities not detectable by standard spirometry generate abnormal acoustic signals. ${ }^{56}$ Our results also demonstrate that, in the absence of a maintenance strategy, the significant effects of PR on respiratory sound parameters are no longer present at 3 months post-PR, whereas in the secondary outcomes, the decline will probably only be noted later. ${ }^{57}$ This finding therefore points to the importance of keeping subjects motivated in changing behaviors after the program to maintain the benefits.

This study has several strengths and limitations. Recordings of respiratory sounds were made in the sitting position on 2 standardized chest locations, in line with the CORSA (Computerized Respiratory Sound Analysis) guidelines. ${ }^{58}$ This will facilitate the comparison of these results with other studies. It could be argued that changes observed in normal and adventitious respiratory sounds after PR could be due to subjects' breathing pattern changes. However, to account for this bias, air flow was standardized during all respiratory sound recordings. Moreover, an analysis of the breathing pattern parameters showed that no changes over time were observed. In addition, respiratory sounds were recorded at an air flow of $0.4-0.6 \mathrm{~L} / \mathrm{s}$, which has already been shown to be reliable in subjects with COPD. ${ }^{27}$ Nonetheless, the interpretation of the results from this study should be tempered, considering the following limitations. Computerized respiratory sounds have high inter-subject variability among subjects with COPD. ${ }^{27}$ To minimize the bias, each subject served as his/her own control, but a control group was not included. Future research examining changes in respiratory acoustics could use crossover designs to overcome the high inter-subject variability of computerized respiratory sounds. ${ }^{27}$ In these studies, any component that is related to the differences between subjects can be removed from comparisons. ${ }^{59}$ To confirm the stability of subjects' respiratory acoustics, 2 baseline computerized respiratory sound recordings were collected with only a 1-week interval. An additional recording (eg, 1 month before the intervention) could have been performed, because symptoms in subjects with COPD are characterized by weekly variability. ${ }^{60}$ However, be- 


\section{RESPIRATORY SOUNDS AS OUTCOMES FOR PR}

cause no research has been conducted on this topic, these limitations do not appear to remove the validity and importance of the results found and will inform further study designs. The sample included mainly subjects with early COPD (mild and moderate); thus, it was not possible to explore how the disease severity related to the sensitivity to change of respiratory sound parameters. Future studies should use a more balanced sample of COPD grades to clarify these findings. This study only assessed the shortand mid-term effects of PR on computerized respiratory sounds; thus, the long-term effects of PR could not be established. Future studies with long-term follow-ups are therefore needed. The complex setup used to record respiratory sounds and air flow can also be seen as a limitation of the study and restricts the application of computerized respiratory sounds in day-to-day clinical practice. Because the use of computerized respiratory sounds shows promise, research should focus in developing technological solutions to acquire respiratory sounds and air flow with minimal setup.

\section{Conclusions}

Median frequency of normal respiratory sounds, mean number of crackles, and wheeze occupation rate were sensitive outcomes to measure the short- and mid-term effects of PR in subjects with COPD. Future research is needed to strengthen these findings and to extend these observations to other clinical interventions and respiratory diseases.

\section{ACKNOWLEDGMENTS}

We thank the individuals who participated in this study and especially thank Joana Cruz and Giovanna Sposito for contributions to the implementation of the PR programs and Ana Oliveira for valuable contributions to data collection.

\section{REFERENCES}

1. World Health Organization. Global surveillance, prevention and control of chronic respiratory diseases: a comprehensive approach. Geneva: World Health Organization; 2007:1-146.

2. Miravitlles M, Murio C, Guerrero T, Gisbert R. Costs of chronic bronchitis and COPD. Chest 2003;123(3):784-791.

3. Global Initiative for Chronic Obstructive Lung Disease. Global Strategy for Diagnosis, Management, and Prevention of Chronic Obstructive Pulmonary Disease 2016. Available from: http://goldcopd.org/.

4. Jones PW, Agusti AG. Outcomes and markers in the assessment of chronic obstructive pulmonary disease. Eur Respir J 2006;27(4):822832

5. Celli BR, Decramer M, Wedzicha JA, Wilson KC, Agustí A, Criner GJ, et al. An official American Thoracic Society/European Respiratory Society statement: research questions in chronic obstructive pulmonary disease. Am J Respir Crit Care Med 2015;191(7):e4-e27.

6. Spruit MA, Singh SJ, Garvey C, ZuWallack R, Nici L, Rochester C, et al. An official American Thoracic Society/European Respiratory Society statement: key concepts and advances in pulmonary rehabilitation. Am J Respir Crit Care Med 2013;188(8):e13-e64.
7. Spruit MA, Pitta F, Garvey C, ZuWallack RL, Roberts CM, Collins EG, et al. Differences in content and organisational aspects of pulmonary rehabilitation programmes. Eur Respir J 2014;43(5):13261337.

8. Camp PG, Appleton J, Reid WD. Quality of life after pulmonary rehabilitation: assessing change using quantitative and qualitative methods. Phys Ther 2000;80(10):986-995.

9. Annesi I, Oryszczyn MP, Neukirch F, Orvoen-Frija E, Korobaeff M, Kauffmann F. Relationship of upper airways disorders to $\mathrm{FEV}_{1}$ and bronchial hyperresponsiveness in an epidemiological study. Eur Respir J 1992;5(9):1104-1110.

10. Bohadana A, Izbicki G, Kraman SS. Fundamentals of lung auscultation. N Engl J Med 2014;370(8):744-751.

11. Sovijärvi ARA, Dalmasso F, Vanderschoot J, Malmberg LP, Righini G, Stoneman SAT. Definition of terms for applications of respiratory sounds. Eur Respir Rev 2000;10(77):597-610.

12. Kiyokawa H, Pasterkamp H. Volume-dependent variations of regional lung sound, amplitude, and phase. J Appl Physiol 2002;93(3): 1030-1038.

13. Fiz JA, Jané R, Homs A, Izquierdo J, García MA, Morera J. Detection of wheezing during maximal forced exhalation in patients with obstructed airways. Chest 2002;122(1):186-191.

14. Sánchez Morillo D, Astorga Moreno S, Fernández Granero MÁ, León Jiménez A. Computerized analysis of respiratory sounds during COPD exacerbations. Comput Biol Med 2013;43(7):914-921.

15. Nici L, ZuWallack R. Pulmonary rehabilitation: today and tomorrow. Breathe 2010;6(4):305-311.

16. Jácome C, Marques A. Short- and long-term effects of pulmonary rehabilitation in patients with mild COPD: a comparison with patients with moderate-to-severe COPD. J Cardiopulm Rehabil Prev 2016;36(6):445-453

17. Thooft A, Favory R, Salgado DR, Taccone FS, Donadello K, De Backer D, et al. Effects of changes in arterial pressure on organ perfusion during septic shock. Crit Care 2011;15(5):R222.

18. Jafari-Khouzani K, Emblem KE, Kalpathy-Cramer J, Bjørnerud A, Vangel MG, Gerstner ER, et al. Repeatability of cerebral perfusion using dynamic susceptibility contrast MRI in glioblastoma patients. Transl Oncol 2015;8(3):137-146.

19. Borg G. Perceived exertion as an indicator of somatic stress. Scand J Rehabil Med 1970;2(2):92-98.

20. Hjermstad MJ, Fayers PM, Haugen DF, Caraceni A, Hanks GW, Loge $\mathrm{JH}$, et al. Studies comparing numerical rating scales, verbal rating scales, and visual analogue scales for assessment of pain intensity in adults: a systematic literature review. J Pain Symptom Manage 2011;41(6):1073-1093.

21. Miller MR, Hankinson J, Brusasco V, Burgos F, Casaburi R, Coates A, et al. Standardisation of spirometry. Eur Respir J 2005;26(2):319338.

22. ATS Committee on Proficiency Standards for Clinical Pulmonary Function Laboratories. ATS statement: guidelines for the six-minute walk test. Am J Respir Crit Care Med 2002;166(1):111-117.

23. American College of Sports Medicine. ACSM's resource manual for guidelines for exercise testing and prescription. Philadelphia: Lippincott Williams \& Wilkins; 2009:324-447.

24. Marshall AL, Smith BJ, Bauman AE, Kaur S. Reliability and validity of a brief physical activity assessment for use by family doctors. $\mathrm{Br} \mathrm{J}$ Sports Med 2005;39(5):294-297; discussion 294-297.

25. Jones PW. St. George's Respiratory Questionnaire: MCID. COPD 2005;2(1):75-79

26. Vyshedskiy A, Murphy R. Crackle pitch rises progressively during inspiration in pneumonia, CHF, and IPF patients. Pulm Med 2012; 2012:240160

27. Jácome C, Marques A. Computerized respiratory sounds are a reliable marker in subjects with COPD. Respir Care 2015;60(9):1264-1275. 


\section{RESPIRATORY SOUNDS AS OUTCOMES FOR PR}

28. Sovijarvi ARA, Vanderschoot J, Earis JE. Standardization of computerized respiratory sound analysis. Eur Respir Rev 2000;10(77): 585.

29. Pinho C, Oliveira A, Oliveira D, Dinis J, Marques A. Lungsounds@UA Interface and Multimedia Database. IJEHMC 2014;5(1):81-95.

30. Quintas J, Campos G, Marques A. Multi-algorithm respiratory crackle detection. Barcelona, Spain: 6th International Conference on Health Informatics (BIOSTEC 2013). Setúbal, Portugal: Institute for Systems and Technologies of Information, Control, and Communication.

31. Taplidou SA, Hadjileontiadis LJ. Wheeze detection based on timefrequency analysis of breath sounds. Comput Biol Med 2007;37(8): 1073-1083.

32. Pasterkamp H, Powell RE, Sanchez I. Lung sound spectra at standardized air flow in normal infants, children, and adults. Am J Respir Crit Care Med 1996;154(2 Pt 1):424-430.

33. Sánchez I, Vizcaya C. Tracheal and lung sounds repeatability in normal adults. Respir Med 2003;97(12):1257-1260.

34. Rovai AP, Baker JD, Ponton MK. Social science research design and statistics: a practitioner's guide to research methods and IBM SPSS analysis. Chesapeake, Virginia: Watertree Press LLC; 2014:260-460.

35. Cohen J. Statistical power analysis for the behavioral sciences. New York: Academic Press; 1969.

36. Gavriely N, Cugell DW. Airflow effects on amplitude and spectral content of normal breath sounds. J Appl Physiol 1996;80(1):5-13.

37. Vyshedskiy A, Alhashem RM, Paciej R, Ebril M, Rudman I, Fredberg JJ, Murphy R. Mechanism of inspiratory and expiratory crackles. Chest 2009;135(1):156-164.

38. Meslier N, Charbonneau G, Racineux JL. Wheezes. Eur Respir J 1995;8(11):1942-1948.

39. Laveneziana P, Parker CM, O’Donnell DE. Ventilatory constraints and dyspnea during exercise in chronic obstructive pulmonary disease. Appl Physiol Nutr Metab 2007;32(6):1225-1238.

40. Malmberg LP, Sovijärvi AR, Paajanen E, Piirilä P, Haahtela T, Katila T. Changes in frequency spectra of breath sounds during histamine challenge test in adult asthmatics and healthy control subjects. Chest 1994;105(1):122-131.

41. Pasterkamp H, Kraman SS, Wodicka GR. Respiratory sounds. Advances beyond the stethoscope. Am J Respir Crit Care Med 1997; 156(3 Pt 1):974-987.

42. Pasterkamp H, Sanchez I. Effect of gas density on respiratory sounds. Am J Respir Crit Care Med 1996;153(3):1087-1092.

43. Jácome C, Marques A. Computerized respiratory sounds in patients with COPD: a systematic review. COPD 2015;12(1):104-112.

44. Piirilä P, Sovijärvi A. Crackles: recording, analysis and clinical significance. Eur Respir J 1995;8(12):2139-2148.

45. Jácome C, Oliveira A, Marques A. Computerized respiratory sounds: a comparison between patients with stable and exacerbated COPD. Clin Respir J 2015. doi: 10.1111/crj.12392.

46. Murphy RL. Special articles: in defense of the stethoscope. Respir Care 2008;53(3):355-369.
47. Piirilä P. Changes in crackle characteristics during the clinical course of pneumonia. Chest 1992;102(1):176-183.

48. Mikelsons $\mathrm{C}$. The role of physiotherapy in the management of COPD. Respir Med COPD Update 2008;4(1):2-7. doi: 10.1016/ j.rmedu.2007.11.021.

49. Ides K, Vissers D, Vissers D, De Backer L, Leemans G, De Backer W. Airway clearance in COPD: need for a breath of fresh air? A systematic review. COPD 2011;8(3):196-205.

50. O'Donnell DE, Flüge T, Gerken F, Hamilton A, Webb K, Aguilaniu $\mathrm{B}$, et al. Effects of tiotropium on lung hyperinflation, dyspnoea and exercise tolerance in COPD. Eur Respir J 2004;23(6):832-840.

51. Ramirez-Venegas A, Ward J, Lentine T, Mahler DA. Salmeterol reduces dyspnea and improves lung function in patients with COPD. Chest 1997:112(2):336-340

52. Dinis J, Oliveira A, Pinho C, Campos G, Rodrigues J, Marques A. Automatic wheeze and respiratory phase detectors to evaluate respiratory physiotherapy in LRTI: a preliminary study. Barcelona, Spain: 6th International Conference on Health Informatics (BIOSTEC 2013). Setúbal, Portugal: Institute for Systems and Technologies of Information, Control, and Communication.

53. Shim CS, Williams MH Jr. Relationship of wheezing to the severity of obstruction in asthma. Arch Intern Med 1983;143(5):890-892.

54. Foglio K, Bianchi L, Bruletti G, Porta R, Vitacca M, Balbi B, Ambrosino N. Seven-year time course of lung function, symptoms, healthrelated quality of life, and exercise tolerance in COPD patients undergoing pulmonary rehabilitation programs. Respir Med 2007; 101(9): 1961-1970.

55. Ries AL, Kaplan RM, Myers R, Prewitt LM. Maintenance after pulmonary rehabilitation in chronic lung disease: a randomized trial. Am J Respir Crit Care Med 2003;167(6):880-888.

56. Gavriely N, Nissan M, Cugell DW, Rubin AHE. Respiratory health screening using pulmonary-function tests and lung sound analysis. Eur Respir J 1994;7(1):35-42.

57. Griffiths TL, Burr ML, Campbell IA, Lewis-Jenkins V, Mullins J, Shiels $\mathrm{K}$, et al. Results at 1 year of outpatient multidisciplinary pulmonary rehabilitation: a randomised controlled trial. Lancet 2000; 355(9201):362-368.

58. Rossi M, Sovijärvi ARA, Piirilä P, Vannuccini L, Dalmasso F, Vanderschoot J. Environmental and subject conditions and breathing manoeuvres for respiratory sound recordings. Eur Respir Rev 2000; 10(77):611-615.

59. Jones B, Kenward MG. Design and analysis of cross-over trials. Boca Raton: CRC Press; 2015:1-10.

60. Kessler R, Partridge MR, Miravitlles M, Cazzola M, Vogelmeier C, Leynaud D, Ostinelli J. Symptom variability in patients with severe COPD: a pan-European cross-sectional study. Eur Respir J 2011; 37(2):264-272.

61. Quanjer PH, Stanojevic S, Cole TJ, Baur X, Hall GL, Culver BH, et al. Multi-ethnic reference values for spirometry for the 3-95-yr age range: the global lung function 2012 equations. Eur Respir J 2012; 40(6):1324-1243 